\title{
EL PAPEL DE LOS PRINCIPIOS FORMALES EN LA PONDERACIÓN DE LOS DERECHOS FUNDAMENTALES. DESAFÍOS A LA PROPUESTA DE ROBERT ALEXY
}

\author{
Juan Bautista Etcheverry \\ CONICET, Universidad Austral, Buenos Aires, Argentina \\ Contacto: jbetcheverry@austral.edu.ar
}

Recibido: 8 de julio de 2021

Aprobado: 22 de julio de 2021

Para citar este artículo:

Etcheverry, J. B. (2021). "El papel de los principios formales en la ponderación de los derechos fundamentales. Desafíos a la propuesta de

Robert Alexy". Prudentia Iuris, N. 92, pp. 221-248

DOI: https://doi.org/10.46553/prudentia.92.2021.pp.221-248

Resumen: Con este trabajo buscamos poner de relieve algunos desafíos que pueden plantearse al modo en que Alexy explica el papel que cumplen los principios formales en la ponderación de los principios materiales. Su propuesta, por un lado, define a los principios formales como aquellos que buscan optimizar la autoridad de las normas debidamente aprobadas y eficaces. Por el otro, le reconoce a los principios formales un papel en la justificación de la variable "fiabilidad epistémica" de las premisas del razonamiento de aplicación/ponderación de los principios materiales. A partir de esto, define al ámbito de competencia discrecional-autoritativo del legislador democrático como aquel que surge fruto de un empate ponderativo o de falta de certeza epistémica sobre las premisas empíricas y normativas que se incorporan a la ponderación. Desarrollada esta propuesta, afirmaremos que ella corre el riesgo de transformarse en una racionalización rígida, artificial y excesivamente refinada.

Palabras clave: Principios formales, Discrecionalidad, Competencia, Ponderación, Determinación, Autoridad. 


\title{
The role of formal principles in weighing fundamental rights. Challenges to Robert Alexy's proposal
}

\begin{abstract}
This paper intends to highlight some challenges that may arise against the way Alexy explains the role that formal principles play in balancing material legal principles. His explanation, on the one hand, conceptualizes formal principles as those that seek to optimize the authority of duly issued and socially efficacious legal norms. On the other hand, he recognizes that formal principles have a role in the justification of the variable "epistemic reliability" of the premises of the reasoning for the application/balancing of material principles. Taking this into account, he defines the scope of discretionary-authoritative competence of the democratic legislator as the one that arises as the result of a balancing stalemate or as the result of a lack of epistemic certainty about the empirical and normative premises that are incorporated into the balance. Having explained Alexy's conception of formal principles, we will argue that it runs the risk of becoming a rigid, artificial, and excessively refined rationalization.
\end{abstract}

Keywords: Formal principles, Discretion, Competence, Balance, Determination, Authority.

\section{Il ruolo dei principi formali nell'equilibrio dei diritti fondamentali. Sfide alla spiegazione di Robert Alexy}

Sommario: Questo articolo intende evidenziare alcune sfide che possono sorgere contro il modo in cui Alexy spiega il ruolo che i principi formali giocano nel bilanciare i principi legali materiali. La sua spiegazione, da un lato, concettualizza i principi formali come quelli che cercano di ottimizzare l'autorità di norme legali debitamente emanate e socialmente efficaci. Riconosce invece che i principi formali hanno un ruolo nella giustificazione della variabile "attendibilità epistemica" delle premesse del ragionamento per l'applicazione/bilanciamento dei principi materiali. Tenendo conto di ciò, definisce l'ambito della competenza discrezionale-autoritativa del legislatore democratico come quello che si pone come risultato di uno stallo equilibratore o come risultato di una mancanza di certezza epistemica circa le premesse empiriche e normative che 
sono incorporate l'equilibrio. Dopo aver spiegato la concezione dei principi formali di Alexy, sosterremo che corre il rischio di diventare una razionalizzazione rigida, artificiale ed eccessivamente raffinata.

Parole chiave: Principi formali, Riservatezza, Competenza, Bilancia, Determinazione, Autorità.

\section{Introducción}

Los mecanismos de control de constitucionalidad creados por las democracias actuales para asegurar la dimensión de corrección del Derecho corren el riesgo de sobredimensionar el rol de los derechos fundamentales en los sistemas jurídicos. La sobreconstitucionalización de dichos sistemas desvaloriza la dimensión autoritativa del Derecho, poniendo en riesgo el Estado democrático de Derecho frente a un posible Estado jurisdiccional de Derecho.

Los intentos por evitar esto proponiendo desconocer por completo la dimensión de corrección del Derecho o considerando que su dimensión autoritativa es la única relevante y necesaria, no explican un aspecto característico de las democracias constitucionales actuales. Por otra parte, quienes buscan solucionar la tensión entre las mencionadas dimensiones autoritativa y de corrección del Derecho afirmando que cuando el Derecho prevé de forma "clara" un caso siempre debe prevalecer la dimensión autoritativa y, en cambio, en los casos dudosos debería prevalecer la dimensión de corrección ${ }^{1}$, tienen el desafío de explicar de un modo menos tosco en qué casos prevalecería una dimensión o la otra ${ }^{2}$.

Alexy busca resolver la aludida tensión acudiendo a lo que ha denominado "principios formales". En concreto, propone que estos principios tengan un papel en la ponderación de los principios materiales. Esto le permite, además, aclarar su "tesis de la discrecionalidad legislativa".

La explicación ofrecida por Alexy puede sintetizarse del siguiente modo: i) define a las normas formales como aquellas que exigen el cumplimiento de las normas que son impuestas por una autoridad legitimada para crearlas; ii) identifica a las normas formales como principios; iii) dentro de los principios formales, destaca el "democrático", según el cual, idealmente,

1 Cfr. Hart, H. L. A. (1983). "American Jurisprudence through English Eyes: The Nightmare and the Noble Dream". En Essays in Jurisprudence and Philosophy. Oxford. Oxford University Press, 123-144.

2 Cfr. Sieckmann, J. (2016). “Principios formales”. En J. Portocarrero (ed.). Ponderación $y$ discrecionalidad. Bogotá. Universidad del Externado, 306. 
el procedimiento de toma de decisiones democrático es el más racional y legítimo que puede existir; iv) propone un modelo que le reconoce un papel a los principios formales al razonamiento de ponderación de los principios constitucionales materiales; v) este modelo es "epistémico" porque considera que los principios formales juegan un papel en la justificación de la variable "fiabilidad epistémica" de las premisas que se incorporan en el razonamiento para aplicar principios materiales y, en particular, en la fórmula con que se ponderan los costos y beneficios de realizar dos principios materiales en colisión; y, a partir de lo anterior, vi) define al ámbito de competencia discrecional-autoritativo del órgano encargado de crear el Derecho como aquel que surge fruto de un empate ponderativo o de falta de certeza epistémica sobre las premisas empíricas y normativas que se incorporan a la ponderación.

Desarrollada la explicación de Alexy sobre cómo se resuelve en el actual contexto institucional la tensión entre las dimensiones de corrección y autoritativa del Derecho, expondremos algunas críticas y desafíos que desde la propia teoría de los principios se le han presentado. En concreto, algunos autores consideran que el modo en que Alexy propone explicar el papel de los principios formales en la ponderación de los materiales parroquializa la teoría de la ponderación, limita indeseadamente la discrecionalidad legislativa, confunde cómo operan los principios formales, le reconoce una autoridad epistémica al legislador que confunde el nivel de la ponderación con el meta-nivel de su conocimiento y no contempla el papel de los principios formales para resolver los problemas de competencias.

A nuestro juicio, la explicación de Alexy resulta rígida y excesiva y artificialmente refinada. Dicho refinamiento, por un lado, la aleja de la experiencia de los operadores jurídicos sobre cómo se aborda la aludida tensión entre las dimensiones autoritativa y de corrección del Derecho y, por el otro, dificulta su capacidad para fundar suficientemente el particular modo en que propone que se relacionan los elementos que componen esta explicación. Además, la rigidez de la explicación propuesta por Alexy le dificulta dar cuenta del distinto modo en que los diferentes sistemas de control de constitucionalidad tienen en cuenta a los principios formales al ponderar los materiales. Finalmente, y en contra de lo que pretendía, la propuesta de Alexy parece terminar estrechando todavía más la discrecionalidad legislativa.

De lo anterior, se concluirá que un modelo alternativo debe tener aspiraciones más modestas en cuanto al nivel de detalle y certeza que es posible ofrecer y debe expresamente ser capaz de reconocer y dar cuenta de los distintos modos razonables de receptar y hacer intervenir a los principios formales en la ponderación de los materiales que recogen los diferentes sistemas de control de constitucionalidad que existen. 


\section{Los principios formales y la discrecionalidad legislativa en Alexy}

\section{Origen, concepto y fundamento de los principios formales}

Ante el riesgo de que se sobredimensione el rol de los derechos fundamentales en el sistema jurídico, sobreconstitucionalizándolo y poniendo en peligro el Estado democrático de Derecho frente a un posible Estado jurisdiccional de Derecho, Alexy considera que la práctica y la teoría constitucional han ofrecido una explicación y fundamentación de la discrecionalidad legislativa basada en lo que denomina "principios formales".

Para Alexy, estos principios exigen el cumplimiento de las normas que son impuestas por una autoridad legitimada para crearlas. Este tipo de norma sería un principio porque es "un mandato de optimización", una norma que exige "que algo sea realizado en la mayor medida de lo posible en función de las posibilidades fácticas y jurídicas"3. Lo particular de los principios formales es el objeto de lo que exige optimizar. Estos principios exigen optimizar "la autoridad de las normas debidamente aprobadas y eficaces"4. "Se refieren a la dimensión real o fáctica del Derecho" y se los denomina "formales" porque el objeto que buscan optimizar "son decisiones jurídicas, independientemente del contenido específico que tengan". Los principios de la "seguridad jurídica" o el de "división de poderes" son ejemplos de este tipo de preceptos ${ }^{5}$. En cambio, los principios materiales o sustantivos exigen optimizar un contenido específico (v. gr., libertad de expresión).

A su vez, estos principios se conectan con el "principio de la democracia". Para Alexy, este principio refiere no solo a la dimensión fáctica o real del Derecho (formal), sino también a una ideal. El principio de la democracia afirma que el procedimiento democrático de toma decisión "es el más racional y legítimo que puede existir". En el contexto de las democracias representativas constitucionales, el principio de la democracia exige que "el legislador democráticamente legitimado sea, en la mayor medida de lo posible, quien tome las decisiones importantes para la comunidad"6. De este modo, no solo le reconoce "autoridad" a las decisiones dictadas por el legisla-

3 Cfr. Alexy, R. "Principios formales. Algunas respuestas a los críticos". En J. Portocarrero (ed.). Ponderación y discrecionalidad. Ob. cit., 34.

4 Ibídem.

5 Cfr. ibídem, 39-40.

6 Ibídem, 35. 
dor democrático dentro de su competencia, sino también exige que el ámbito de la discrecionalidad legislativa "sea tan amplia como sea posible"7.

\section{Dos tipos de discrecionalidad legislativa}

Para Alexy, el aludido margen de discrecionalidad legislativa puede surgir por diferentes motivos. Por un lado, hay cosas que la constitución "no manda o prohíbe de manera definitiva". "Lo que no está ni prohibido ni

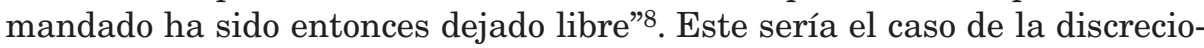
nalidad material o estructural.

Por otra parte, para Alexy, la discrecionalidad legislativa también surge cuando el conocimiento de lo que manda, prohíbe o deja libre la constitución es incierto. En estos casos, el legislador tendría discrecionalidad epistémica para determinar lo prohibido, mandado o dejado libre.

Según Alexy, “que el legislador sea libre donde no existen obligaciones no requiere ser justificado". En cambio, la afirmación de que el legislador es libre cuando no tiene elementos que le den certeza sobre si está o no obligado por la constitución necesita fundarse en los principios formales ${ }^{9}$.

Resta mencionar que, a juicio de Alexy, esta discrecionalidad epistémica puede surgir por dos motivos. Por un lado, por incertidumbre empírica acerca de si una medida es idónea para alcanzar un determinado fin constitucional o sobre si es necesaria; es decir, es la menos restrictiva del Derecho que afecta. Por el otro, por existir incertidumbre empírica o normativa sobre con qué intensidad la medida en cuestión afecta un derecho o realiza el principio en el que se funda.

\section{El papel de los principios formales en la ponderación de los principios materiales}

a) ¿Son los principios formales y los materiales inconmensurables?

Lo primero que Alexy quiere aclarar es que es posible ponderar principios formales con principios materiales. Dicho de otra manera, sostiene que estos principios no son inconmensurables. Para mostrar esto, acude a

7 Ibídem, 36 .

8 Ibídem, 43.

9 Cfr. ibídem, 44. 
algunos ejemplos jurisprudenciales posteriores a la caída del nacionalsocialismo en 1945 y de la República Democrática Alemana en 1989, en los que se aplicó la fórmula de Radbruch. Esta fórmula es el resultado de ponderar el principio material de justicia y el formal de seguridad jurídica. De esta ponderación se concluye que en los casos en los que la injusticia no es extrema prevalece la seguridad jurídica sobre la justicia. En cambio, en los casos en los que la injusticia es extrema, prevalece la justicia por sobre la seguridad jurídica. Esta ponderación es sintetizada en la formulación: "La injusticia extrema no es Derecho"10.

\section{b) El papel de los principios formales en una ponderación de segundo orden}

Para Alexy, los principios formales juegan un papel particularmente importante en la justificación de la variable "fiabilidad epistémica" de la fórmula con la que se ponderan los costos de afectar y los beneficios de realizar dos principios en colisión en unas circunstancias concretas. Por medio de dicha fórmula se busca esclarecer cuál de tales principios pesa más o ha de ser preferido en las circunstancias concretas en las que se realiza la ponderación. En este sentido, los principios formales tendrían un rol especial en la ponderación de segundo orden que busca justificar la fiabilidad de las premisas fácticas y normativas que se incorporan a la ponderación entre principios (o ponderación de primer orden).

La ponderación de segundo orden sopesa, por un lado, "el principio formal del legislador democráticamente legitimado" y, por el otro, el "mandato de optimización epistémico" que surge de todo derecho fundamental ${ }^{11}$. Para Alexy, estos últimos son mandatos de optimización material y epistémico porque "la realización de los derechos fundamentales se incrementa cuando ellos son limitados solo en virtud de premisas cuya certeza o verdad está asegurada. Si a pesar de ello se admitiesen premisas cuyo nivel de certeza está por debajo del nivel de seguridad absoluta, la realización de los derechos fundamentales se incrementaría cuando se escojan premisas que sean lo más favorable posible para la realización de los derechos fundamentales"12.

Por otra parte, sostiene que los intentos por resolver esta colisión entre principios formales y materiales estableciendo una precedencia absoluta 0 rígida producirían resultados inaceptables. Si se otorgare dicha preceden-

10 Ibídem, 37.

11 Cfr. ibídem, 48.

12 Ibídem, 47. 
cia a los principios materiales que recogen derechos fundamentales, esto produciría una "total parálisis legislativa" que afectaría desproporcionadamente a los mencionados principios formales. Esto sería así debido a que en muchas áreas del Derecho prácticamente no existen premisas que sean absolutamente verdaderas. $\mathrm{Si}$, en cambio, la precedencia rígida se otorgare en favor de los principios formales, en este caso se permitiría que el legislador base su afectación de un derecho fundamental en premisas inciertas e, incluso, falsas. Esto supondría desconocer que estos derechos exigen para sí el mayor grado de realización posible en función de las circunstancias fácticas y jurídicas del caso concreto. Más específicamente, supondría desconocer que los derechos fundamentales exigen tanto una optimización material como una epistémica ${ }^{13}$.

\section{c) La ley de colisión de segundo orden}

Alexy propone superar los problemas anteriormente expuestos acudiendo a una ponderación de segundo orden entre el principio formal del legislador democráticamente legitimado y el mandato de optimización epistémico que emana de todo derecho fundamental. Se espera que de esta ponderación surja una relación de preferencia condicionada.

Según Alexy, dicha relación sería del siguiente modo: i) ante una premisa empírica "cierta" que favorece al principio material en colisión, dicho principio tiene precedencia sobre el principio formal; en cambio, ii) si la premisa empírica que favorece al principio material en colisión es "plausible" o "solo no evidentemente falsa", tiene precedencia el principio formal ${ }^{14}$. Por ejemplo, si dos premisas contrapuestas tienen el mismo valor epistémico, supongamos "plausibles", entonces existiría un empate epistémico y, en estos casos, el legislador tendría "discrecionalidad epistémica" por el peso del principio formal. Si no existiese el principio formal, el principio material (que contiene un mandato de optimización epistémico) exigiría que la premisa que le resulte más favorable sea adoptada ${ }^{15}$.

Sin embargo, esta precedencia no ofrece un peso concreto de los principios materiales en colisión. Esto requiere su combinación con otros elementos recogidos en lo que Alexy denomina como la "fórmula del peso refinada". Dicha fórmula combina variables materiales y epistémicas y, por tanto, pre-

13 Cfr. ibídem, 47-48.

14 Cfr. ibídem, 50.

15 Cfr. ibídem, 56. 
tende conectar la ponderación material o de primer orden con la epistémica o de segundo orden ${ }^{16}$.

\section{d) La fórmula del peso refinada}

Esta fórmula permitiría, según Alexy, alcanzar el peso concreto de un principio material $(\mathrm{Pi})$ en relación con otros principios contrapuestos $(\mathrm{Pj})$. Dicho resultado se obtendría de dividir tres factores. Por un lado, la intensidad con que se interfiere o afecta un derecho fundamental (Ii), dividido la importancia de realizar un principio contrapuesto (Ij). En segundo lugar, se dividen los pesos en abstracto de los principios contrapuestos (Gi y Gj). Suele ocurrir en la colisión de derechos fundamentales que el peso en abstracto de estos principios es igual y, por tanto, se anulan mutuamente. Por último, se divide la fiabilidad de las asunciones empíricas $\left(\mathrm{Se}^{\mathrm{i}}\right) /\left(\mathrm{Se}_{\mathrm{j}}\right)$ y normativas

$\left(\mathrm{S}_{\mathbf{i}}\right) /\left(\mathrm{S}_{\mathbf{j}}\right)$ que giran en torno de cuán intensa es la interferencia en cada uno de los principios o su peso abstracto. Este factor no es ontológico o se refiere a objetos, sino a su conocimiento y, por tanto, es epistémico.

Resta mencionar que Alexy propone una escala triádica de intensidades de afectación e importancia de realizar un principio y de su peso en abstracto: leve, moderado y grave. A su vez, le atribuye un valor numérico a esta escala 1, 2 y 4. En lo relativo a la cuestión epistémica sugiere trabajar con la escala de valores: confiable o cierto, plausible y no evidentemente falso. Por último, su valor numérico sería: $1,1 / 2$ y $1 / 4{ }^{17}$.

De este modo, "la fórmula del peso refinada" es expresada por Alexy mediante la siguiente ecuación:

$$
G i, j=\frac{\mathrm{Ii} \cdot \mathrm{Gi} \cdot \mathrm{Se}^{\mathrm{i}} \cdot \mathrm{Sn}_{\mathrm{i}}}{\mathrm{Ij} \cdot \mathrm{Gj}_{\mathrm{j}} \cdot \mathrm{Sej} \cdot \mathrm{Sn}_{\mathrm{j}}}
$$

\section{e) Un ejemplo de aplicación de la fórmula del peso refinada y del papel o importancia de los principios formales}

Un ejemplo de la posible aplicación de la fórmula del peso refinada a un caso de interés en la actualidad es el relativo al debate sobre la constitucionalidad de las "medidas de aislamiento social obligatorio" que mu-

16 Cfr. ibídem, 51.

17 Cfr. ibídem, 33. 
chos gobiernos han tomando a lo largo del mundo por la expansión del COVID-19. Este ejemplo, además de ser de incuestionable interés no solo local sino mundial, permite ver con mucha claridad cuál sería el papel que Alexy le atribuye a los principios formales y a la discrecionalidad epistémica del Poder Legislativo, cuando existen dudas sobre la fiabilidad de las premisas empíricas y normativas que se han de tener en cuenta para ponderar unos principios en un caso en concreto.

Es obvio que la constitucionalidad de las restricciones que impusieron muchos Estados con la finalidad de proteger la "salud pública" depende en gran parte de cómo cada constitución distribuye las competencias para tomar este tipo de decisiones, del tipo concreto de medidas que cada Estado haya tomado, de qué derechos afecten y de cómo han sido receptados constitucional y jurisprudencialmente esos derechos. Sin embargo, es posible encontrar algunos aspectos relativamente comunes de las medidas preventivas que tomaron muchísimos Estados. En este ejercicio, tomaremos como medida a determinar su constitucionalidad "la limitación a la autonomía que supone la prohibición de circulación, reunión, realización de tareas, práctica de deportes, etc.”, que impusieron muchos Estados. Supondremos, además, que la mayoría de los Estados tienen incorporado en sus constituciones el "derecho a la autonomía personal" y que el órgano que dictó la medida es el competente a tal efecto. En definitiva, aislaremos nuestro ejemplo de otros posibles problemas constitucionales para centrarnos en la discusión sobre la constitucionalidad de una medida que afecta la "autonomía personal" fundada en el principio de la "protección de la salud pública".

En este caso, para definir la constitucionalidad de la medida que restringe la autonomía personal debemos, en primer lugar, establecer si dicha medida persigue una finalidad constitucional. Podemos presuponer que el objetivo de ella es constitucional porque persigue la protección de la salud pública frente a una pandemia y que sin dicha protección especial el sistema de salud puede no ser capaz atender a todas las personas enfermas que lo requieran. A su vez, debemos establecer si esta medida es adecuada para lograr el fin constitucional perseguido. De lo contrario, la restricción o afectación al derecho constitucional de autonomía no tendría sentido o carecería de fundamento. Supongamos nuevamente que limitar la autonomía de las personas permite limitar la circulación, en este caso, del virus y, por tanto, contribuye a que la pandemia no se propague.

Si damos por supuesto que las mencionadas limitaciones a la autonomía son adecuadas para lograr proteger la salud pública, todavía queda por definir si esta restricción al derecho a la autonomía es necesaria. Dicho de otro modo, resta establecer si no existen medidas igualmente adecuadas para alcanzar el fin de la protección de la salud pública, aunque menos restrictivas del derecho a la autonomía personal. Surgen, en este punto, una 
serie de problemas para definir la cuestión. Dividiremos estos problemas en dos grupos. Por un lado, los problemas relativos a las particularidades locales de cada sociedad en las que se aplican estas medidas para definir si ellas son necesarias o no. Por el otro, problemas de "fiabilidad" de las premisas, en este caso empíricas, que se han de tener en cuenta para establecer si restringir la autonomía de las personas es o no necesario para evitar la propagación del virus y, así, proteger la salud pública. En este sentido, la bibliografía científica no es uniforme y ha ido evolucionando de forma oscilante dada la falta de conocimiento previo sobre este virus.

Supongamos nuevamente que la medida restrictiva de la autonomía es necesaria. Resta todavía establecer si, además de adecuada y necesaria, es proporcionada. Es decir, si la intensidad con que se interfiere el derecho a la autonomía personal en nuestro caso es proporcional a la importancia de satisfacer la salud pública en las mencionadas circunstancias. Para ello, debemos establecer si el peso abstracto de los principios salud pública y derecho a la autonomía son iguales o diferentes. Además, debemos establecer en unas circunstancias concretas si la intensidad de la afectación al derecho a la autonomía y la importancia del bien salud pública son leves, moderadas o graves. Por último, es necesario definir la certeza, o la solo plausibilidad, o la no evidentemente falsedad de las premisas empíricas y normativas que se discuten a fin de optimizar los principios en colisión.

Supongamos, una vez más, que la importancia en abstracto tanto de la salud pública como de la autonomía es la misma. Dado el empate en el peso abstracto de estos principios, estas variables se anularían.

A su vez, también es posible asumir que la restricción a la autonomía impuesta por estas medidas es grave. Sin embargo, supongamos que existe un debate acerca de la importancia de proteger la salud pública en estas circunstancias de la manera propuesta.

En estas situaciones, pareciera que lo que termina de definir la proporcionalidad de la medida es la seguridad o certeza de las premisas que se necesitan para ponderar los principios en juego.

Supongamos que las premisas empíricas existentes para defender tanto la importancia media como alta de restringir la autonomía de la manera mencionada para garantizar la salud pública son solo plausibles. Si este fuera el caso, para Alexy, cuando dos asunciones contrapuestas tienen el mismo valor epistémico, entonces se produce un empate epistémico y, en estos casos, el legislador tendría "discrecionalidad epistémica" por el peso de los principios formales. A su vez, como se vio anteriormente, si no existiesen los principios formales, el Derecho constitucional (que contiene un mandato de optimización también epistémico) exigiría que la premisa que le resulte más favorable sea adoptada. 
El análisis de constitucionalidad de la medida hasta aquí propuesto podría expresarse gráficamente del siguiente modo

$$
\begin{aligned}
\mathrm{Pa}, \mathrm{sp}= & \frac{\mathrm{Ia} \cdot \mathrm{Ga} \cdot \mathrm{S}^{\mathrm{e}} \mathrm{a} \cdot \mathrm{S}^{\mathrm{n}} \mathrm{Isp} \cdot \mathrm{Gsp} \cdot \mathrm{S}^{\mathrm{e}} \mathrm{sp} \cdot \mathrm{S}^{\mathrm{n} p}}{\mathrm{Isp}} \\
\mathrm{Pa}, \mathrm{sp}= & \frac{2 \cdot 4 \cdot 1 \cdot 1}{4 \cdot 4 \cdot 1 / 2 \cdot 1}=1
\end{aligned}
$$

El resultado de peso concreto 1 refleja un "empate ponderativo". Es decir, el legislador tendría en este caso "discrecionalidad estructural”. Más específicamente, en este ejemplo, la llamada discrecionalidad estructural que tiene el legislador se nutre o, en parte, está compuesta de la "discrecionalidad epistémica" de la que también goza. Esta discrecionalidad se refleja en que, si bien es solo plausible la seguridad epistémica de la premisa según la cual existe un grave riesgo para la salud pública frente a la pandemia COVID-19 (no existe conocimiento científico que lo avale definitivamente), siendo también plausible la premisa que afirma que el riesgo para la salud pública es solo moderado, por el principio formal se le reconoce al órgano legitimado democráticamente la facultad de desempatar esta cuestión. Adviértase que la constitucionalidad de la medida va a depender, en este caso, en parte, del grado de seguridad que se le reconozca a la premisa "es grave o moderadamente peligroso para la salud pública la pandemia COVID-19".

En definitiva, en nuestro ejemplo, la afectación descrita de la autonomía en el contexto de la pandemia COVID-19 quedaría en el ámbito de la discrecionalidad del órgano democráticamente legitimado para tomar esta decisión. Sería, por lo tanto, constitucional. Si el resultado fuese mayor que 1 , tendría prioridad en las circunstancias del caso el derecho a la autonomía, y si fuera menor que 1 , la salud pública.

\section{Desafíos al "modelo epistémico" que propone Alexy para explicar el papel de los principios formales en la ponderación de los principios materiales}

Desde la propia teoría de los principios se han ofrecido una serie de críticas al papel que Alexy les atribuye a los principios formales en la pon- 
deración de los principios materiales ${ }^{18}$. De todas las críticas que ha recibido, destacaremos solo algunas de ellas. En concreto, nos detendremos en seis. Denominaremos a estas críticas del siguiente modo: i) el problema de la parroquialización de la teoría de la ponderación; ii) la limitación indeseada de la discrecionalidad legislativa; iii) el funcionamiento de los principios formales como una regla; iv) el tipo de autoridad (epistémica o de otra clase) que se le reconoce al legislador; v) la posibilidad de ponderar principios formales para resolver problemas de competencia; y vi) los riesgos de caer en un modelo rígido y excesiva y artificialmente refinado.

\section{El problema de la parroquialización de la teoría de la ponderación}

Una de las objeciones que ha recibido la incorporación que Alexy propone de los principios formales (en concreto, el principio de la democracia) en la ponderación es que la parroquializa o des-universaliza. Esto sería así porque incorpora un elemento a la ponderación (el peso que supone que la legislación que se pondera sea de origen democrático) que no necesariamente se encuentra en todo caso que se necesite ponderar principios materiales. Por ejemplo, puede que resulte necesario ponderar principios en contextos en que el Derecho no sea de origen democrático o no emane del órgano democrático más representativo (Poder Legislativo).

$\mathrm{Al}$ respecto, Sieckmann sostiene que si bien la "fórmula del peso" había sido presentada por Alexy como la "correspondencia aritmética del esquema deductivo", "[d]ebido a que la lógica y la aritmética no son utilizables únicamente en democracias", con la incorporación de los principios formales en la "fórmula del peso" ella pierde su "estatus de validez universal y ley cuasi lógica"19.

En síntesis, con la incorporación de elementos locales y contingentes a la ponderación (como el peso de la democracia en las decisiones de los tribunales) el enfoque de Alexy deja de ser universal.

18 Un libro editado por Portocarrero recoge varios trabajos en los que desde la propia teoría de los principios se critica cómo Alexy propone incorporar los principios formales a la ponderación. Cfr. J. Portocarrero (ed.). Ponderación y discrecionalidad. Ob. cit., passim.

19 Sieckmann, J. "Principios formales". Ob. cit., 291. 
JUAN BAUTISTA ETCHEVERRY

\section{La limitación indeseada de la discrecionalidad legislativa}

Borowski advierte que incorporar la variable "seguridad" a la fórmula del peso no amplía la discrecionalidad legislativa basada en un principio formal, sino que hace lo contrario. En concreto, sostiene que la fórmula del peso se complejiza al agregarle la variable "seguridad" (tanto de las premisas fácticas como de las jurídicas). Esto limita mucho la probabilidad de un empate ponderativo. Justamente, es en el ámbito de dichos empates en el que el Poder Legislativo ejerce su legítima discrecionalidad. En estos casos, la constitución no manda ni prohíbe de manera definitiva algo. Dado que lo que no está ni prohibido ni mandado ha sido dejado libre, entonces el legislador puede elegir discrecionalmente cómo ordenar aquello que el constituyente no prohibió ni mandó 20 .

Si bien Borowski tiene razón al advertir que la incorporación de la variable seguridad en la fórmula del peso limita la discrecionalidad estructural o material, hay que reconocer que Alexy pretende habilitar con esta incorporación otro tipo de discrecionalidad: la epistémica. Como se explicó, esta discrecionalidad surgiría cuando dos asunciones contrapuestas sobre la seguridad de las premisas fácticas o normativas que se tienen en cuenta en la ponderación tienen el mismo valor epistémico, entonces se produce un empate epistémico y, en estos casos, el legislador tendría "discrecionalidad epistémica” por el peso del principio formal de la democracia.

\section{El funcionamiento de los principios formales como una regla}

Otra crítica que recibe la propuesta de Alexy pone en duda que el peso de los denominados principios formales en la ponderación requiera ser graduado como él sugiere. Por ejemplo, Portocarrero sostiene que el peso de estas normas permanece constante y se encuentra en el meta-nivel epistémico representado por las variables "S" en la fórmula del peso. Según este autor, dado que estas normas no se opondrían con ningún otro principio material, alcanzarían su grado máximo de optimización y permanecerían de esa manera de forma constante. Esto supone que funcionan como reglas que "exige[n] el cumplimiento de las decisiones del legislador ante la falta de certeza epistémica respecto de las premisas que sustentan su decisión".

20 Borowski, M. "Principios formales y fórmula del peso". En J. Portocarrero (ed.). Ponderación y discrecionalidad. Ob. cit., 112. 
Más específicamente, y a diferencia de Alexy, para Portocarrero estas normas operan o son relevantes cuando el grado de certeza epistémica sobre una premisa es "no evidentemente falso". Dicho de otro modo, no son relevantes cuando el grado de certeza epistémica sobre una premisa es "seguro". En este caso, no serían relevantes porque no se produce una falta de certeza.

En síntesis, para autores como Portocarrero los principios formales son relevantes cuando la certeza de una premisa que sustenta una decisión legislativa es "no evidentemente falsa", permitiendo estos principios que, incluso en este caso, se pueda dar prioridad a la autoridad del Derecho (in dubio pro legislatore $)^{21}$.

\section{El tipo de autoridad (epistémica o de otra clase) del legislador}

El enfoque epistémico de Alexy sobre cómo incorporar a los principios formales en la ponderación de principios materiales defiende que solo sirven cuando no es posible conocer de forma segura o clara qué dispone la constitución. En otras palabras, por estos principios, una ley no puede ser declarada inconstitucional sin algún tipo de seguridad al respecto. La fórmula del peso refinada exige a quien considera que la afectación de un derecho es grave, pero su valoración de dicha gravedad solo plausible, afectar esa valoración y volverla diferente al propio juicio.

Para Sieckmann, las razones necesarias para fundar la relevancia de las premisas inseguras no están en que quien definió esto es el legislador o en que tiene una especial legitimidad lo que defina. Estas razones solo las podrían aportar los principios en competencia con los derechos fundamentales, que sirven como razones de afectación. A su vez, para Sieckmann ni de la importancia de la protección constitucional ni de lo que surge de los principios en competencia puede justificarse no usar en la ponderación las premisas mejor fundadas. Para este autor, según las reglas de la argumentación y de la carga de la prueba, incluso cuando dichas premisas son igualmente justificables, debería concluirse que en ese caso no puede fundarse una lesión a los derechos fundamentales. El modelo "epistémico" pareciera permitir apartarse del supuesto mejor fundado solo porque el legislador así lo desea, sin aportar las razones materiales para ello. En definitiva, todo esto ocurriría, porque confunde la ponderación de primer nivel-ontológica,

21 Cfr. Portocarrero, J. "El problema de los principios formales en la doctrina de la ponderación de Robert Alexy: Del in dubio pro libertate al in dubio pro legislatore". En J. Portocarrero (ed.). Ponderación y discrecionalidad. Ob. cit., 247-249. 
con la cuestión epistémica. "No se distingue el nivel del objeto del metanivel". Y, a su vez, se confunde el nivel volitivo-discrecional con el intelectivo, del conocimiento de las premisas ${ }^{22}$. Para Sieckmann, lo relevante con relación a los principios formales es el conflicto de pretensiones legítimas entre el Poder Legislativo y el de los tribunales con jurisdicción constitucional. Sin embargo, esto es el centro de un enfoque normativo y no meramente epistémico, como el que defiende Alexy.

\section{La posibilidad de ponderar principios formales para resolver problemas de competencia}

Para varios autores, el enfoque "epistémico" de Alexy, que pretende incorporar a los principios formales en la ponderación de los principios materiales, no logra abordar la cuestión central de los principios formales: la ponderación de las normas de competencia cuando entran en conflicto.

Según esta visión, los principios formales son un instrumento para una adecuada delimitación de competencias de ponderación y de toma de decisiones. Un sistema constitucional sin principios formales ofrecería "soluciones extremas" en la distribución de competencias: o bien los tribunales con jurisdicción constitucional deberían decidir de forma material, incluso en caso de dudas o cuando es ampliamente discutida la afectación de un derecho fundamental; o bien retirarse en estos casos y no ponderar tal afectación. Este tipo de soluciones no parecen ser compatibles con el Estado de Derecho Constitucional. En cambio, se afirma que una solución más acorde con esta forma de organización política y jurídica sería la ponderación de los principios formales en colisión: aquellos en los que descansan la legitimidad democrática del legislador y de los tribunales como intérpretes autorizados y vinculantes de la constitución ${ }^{23}$.

\section{Los riesgos de un modelo rígido, excesiva y artificialmente refinado}

Hasta aquí hemos visto que una preocupación creciente en los sistemas constitucionales de derecho actuales es que se desnaturalicen y terminen transformándose o mutando de un Estado democrático de Derecho hacia un posible Estado jurisdiccional de Derecho. Frente a esta preocupación, varios

22 Sieckmann, J. "Principios formales" Ob. cit., 295-297.

23 Cfr. ibídem, 297 y ss. 
de los principales teóricos que buscan explicar y comprender las características centrales de los sistemas constitucionales actuales revalorizan o reconocen haber omitido la relevancia del papel de los principios formales en la aplicación de los principios constitucionales materiales.

Alexy es uno de los autores que reformula el papel que le reconocía a los principios formales en la aplicación de los materiales. El modelo propuesto por él es denominado "epistémico". Este modelo incorpora indirectamente a los principios formales en la aplicación de los principios materiales. En concreto, propone que cumplan un rol en caso de que haya dudas epistémicas sobre la certeza de las premisas fácticas y normativas que se tienen en cuenta a la hora de aplicarlos.

Entre otras críticas que ha recibido este modelo, se ha argumentado que es parroquial o no general, que al final de cuentas termina acotando todavía más la discrecionalidad del Poder Legislativo democrático frente al jurisdiccional, que los principios formales en la aplicación de los materiales en realidad funcionan como una regla, que confunde el nivel volitivo-discrecional con el intelectivo-del conocimiento de las premisas y, por último, que no ofrece soluciones a los problemas de conflictos de competencia.

A nuestro juicio, el principal defecto del modelo "epistémico" de Alexy es que, si bien reconoce la importancia de los principios formales y de la discrecionalidad legislativa, al final de cuentas propone un modo rígido, excesiva y artificialmente refinado de combinar la ponderación de los principios materiales con los formales.

\section{a) Un modelo excesiva y artificialmente refinado}

En primer lugar, el modelo propuesto por Alexy complejiza o refina de tal manera la fórmula del peso, al punto de transformarla en una ecuación aritmética tan enrevesada que cada vez menos se parece o explica la experiencia real de los operadores jurídicos cuando aplican principios materiales y, para ello, también tienen en cuenta a los principios formales. En este sentido, puede decirse que el modelo epistémico de Alexy yerra por exceso.

Para mostrar esto alcanza con advertir cómo Alexy pasa de describir el modo en que el Tribunal Constitucional alemán tiene en cuenta cuando se discute la certeza de las premisas empíricas de una ponderación, que dichas premisas hayan sido presentadas por el legislador democrático; a proponer un modelo que incorpora en la fórmula del peso las variables seguridad epistémica fáctica y normativa. A su vez, Alexy continúa avanzando más allá del ejemplo ofrecido y define que dichas variables tendrán tres niveles de escala epistémica. Finalmente, le asigna un valor numérico a cada una de esas escalas $(1,1 / 2$ y $1 / 4)$, que resulta ser específicamente un cuarto del 
valor numérico que le asigna a las escalas de importancia o afectación de un derecho $(4,2,1)$. Como es fácil de observar, parece haber un abismo entre, por un lado, reconocerle un papel a los principios formales en la ponderación de los materiales cuando existen dudas epistémicas; y, por el otro, sostener que por la ponderación de segundo orden entre el mandato de optimización epistémico recogido en los principios materiales y el mandato de optimizar la legislación democrática recogido por los principios formales, la fórmula del peso debe incorporar las variables de seguridad epistémica fáctica y normativa, con tres niveles cada una de ellas, a las que se les atribuyen valores numéricos y que en conjunción con el resto de los elementos que se ponderan son posibles hasta seis mil quinientos sesenta y un posibilidades combinatorias de estas variables ${ }^{24}$.

Si bien la fórmula del peso puede ser entendida de modo tal que solo haga un "uso metafórico del lenguaje matemático"25, dado que la figura con la que se elige comparar el razonamiento necesario para ponderar los principios es un algoritmo inventado a ese efecto, deben justificarse suficientemente sus partes y la relación entre ellas. Aunque se compartan los temas o problemas (peso de los derechos considerados en abstracto, su afectación o satisfacción en el caso concreto, fiabilidad de las premisas que se sopesan) a los que remiten los elementos de la fórmula del peso, la relación entre estos elementos no parece del todo justificada.

\section{b) Un modelo rígido}

En segundo lugar, el modelo de Alexy no permite tener en cuenta las particularidades de los diferentes sistemas constitucionales a fin de explicar y fundar el papel de los principios formales en la ponderación de los ma-

24 Cfr. Alexy, R. "Principios formales. Algunas respuestas a los críticos". Ob. cit., 44 y ss. Entre otros autores, García Amado sostiene que la metodología algorítmica de la ponderación colabora a que los jueces obvien la argumentación de algunas de sus elecciones. Si bien en general no compartimos la crítica de García Amado a la ponderación, en la medida en que el modelo de Alexy se vuelve cada vez más artificial y excesivamente refinado se incrementa el riesgo advertido por el autor español. Cfr. García Amado, J. A. (2007). "El juicio de ponderación y sus partes. Una crítica”. En R. Alexy (ed.). Derechos sociales y ponderación. $2^{\mathrm{a}}$ ed. Madrid. Fundación Coloquio Jurídico Europeo, 250.

25 Atienza, M. (2010). "A vueltas con la ponderación”. Anales de la Cátedra de Francisco Suárez 44, 50. Si bien Bernal Pulido expresamente afirma que hace un uso metafórico del lenguaje matemático en su propuesta de fórmula del peso, dicha propuesta complejiza todavía más la de Alexy. En concreto, para determinar el grado de afectación e importancia de un derecho propone tener en cuenta la eficacia, velocidad, probabilidad, alcance y duración de la medida que afecta o satisface un derecho. Cfr. Bernal Pulido, C. (2006). "La racionalidad de la ponderación”. Revista Española de Derecho Constitucional 77, 67 y ss y n. 53. 
teriales. En otras palabras, oscurece elementos relevantes de los diferentes sistemas para explicar el papel de los principios formales en la ponderación de los materiales. Si bien la propuesta de Alexy tiene en cuenta que el origen democrático de la legislación pesa (y hay razones para que así sea) en la ponderación de su constitucionalidad, no incluye o prevé cómo incluir en ese balance las particularidades de los diferentes sistemas constitucionales. En este sentido, podríamos decir que su modelo termina siendo rígido.

El grado de discrecionalidad reconocido al legislador no es igual en todos los sistemas constitucionales. Reflejo de ello es que los sistemas constitucionales son más o menos reglados. A su vez, los sistemas de control de constitucionalidad que incorporan los diferentes sistemas constitucionales tampoco son todos iguales. Entre otras cosas se diferencian según el órgano que ejerce el control (no judicial o judicial y, dentro de este último, difuso, concentrado o mixto), según sus consecuencias (preventivo, reparador o mixto), según el modo en que se impugna una norma (abstracto o para un caso concreto), según sus efectos (para un caso o con efectos erga omnes), según la temporalidad de sus efectos (retroactivos o no retroactivos), etc. Dichos sistemas de control de constitucionalidad suelen ofrecer diferente peso o mecanismos de protección a distintos tipos de derechos, incluyen consuetudinariamente o formalmente diferentes reglas procesales que regulan la intensidad y el tipo de premisas a las que se les aplica la presunción de constitucionalidad de la legislación democrática, etc. ${ }^{26}$.

La mencionada presunción de constitucionalidad es recogida como una regla que impone al actor que impugna la constitucionalidad de una ley la "carga de argumentar" o de ofrecer razones por las que encuentra inconstitucional la cuestionada ley ${ }^{27} \mathrm{y}$, en algunos casos, incluso como una regla que impone la "carga de probar" los hechos en los que se apoyan sus argumentaciones, estando obligado solo a probar los hechos positivos que alega ${ }^{28}$.

Para advertir la rigidez del modelo de Alexy alcanza con mostrar que resulta incapaz de tener en cuenta que algunos sistemas reconocen más deferencia a las premisas empíricas sobre las que descansa la legislación

26 Por ejemplo, en Estados Unidos la presunción de constitucionalidad es un límite autoimpuesto por los jueces que llevan a cabo el control de constitucionalidad. Cfr. Hessick, F. A. (2010). "Rethinking the Presumption of Constitutionality". Notre Dame Law Review 85, 1447.

27 Cfr. Sánchez Gil, R. "La presunción de constitucionalidad”. En E. Ferrer Mac-Gregor y A. Zaldívar Lelo de Larrea (coords.). La ciencia del derecho procesal constitucional. Estudios en homenaje a Héctor Fix-Zamudio en sus cincuenta años como investigador del Derecho. T. VIII. México. UNAM, 375 y ss. 77,410 .

28 Cfr. Rivers, J. (2014). "The Presumption of Proportionality". The Modern Law Review 
democrática que a las premisas normativas ${ }^{29}$. En concreto, el sistema de control de constitucionalidad norteamericano funciona con una regla autoimpuesta por los órganos encargados de realizar el mencionado control que establece que los jueces no necesitan evaluar los hechos para determinar si una ley es un medio razonable para lograr un interés legítimo del Estado. Según esta regla, derivada de la presunción de constitucionalidad de las leyes, en la medida que un tribunal puede concebir un grupo de hechos que permita establecer lo razonabilidad de la legislación, ella sería constitucional. En cambio, los tribunales norteamericanos no han reconocido la misma deferencia en relación a las interpretaciones sobre el contenido de la Constitución que hace el Poder Legislativo. De hecho, la Corte Suprema de Estado Unidos ha sostenido reiteradamente que es la "autoridad última" para interpretar la Constitución ${ }^{30}$.

En definitiva, el modelo de Alexy propone tener en cuenta el papel de los principios formales en la ponderación de los materiales, receptando a la variable "fiabilidad epistémica" (seguridad de las premisas fácticas y jurídicas) en la fórmula con la que se ponderan los costos de afectar y los beneficios de realizar dos principios en colisión en unas circunstancias concretas. Para ello, concluye que cuando dos asunciones contrapuestas tanto sobre premisas fácticas como jurídicas tienen el mismo valor epistémico, entonces se produce un empate epistémico y, en estos casos, el legislador tendría "discrecionalidad epistémica" por el peso de los principios formales. Sin embargo, como se acaba de explicar, algunos sistemas reconocen más deferencia a las premisas empíricas sobre las que descansa la legislación democrática que a las premisas jurídicas. Este tipo de particularidades son las que la rigidez del modelo de Alexy no logra tener en cuenta.

Por otra parte, las cargas de argumentar y/o de probar que puede imponer la presunción de constitucionalidad también suelen verse afectadas según los derechos que restrinja la legislación cuestionada. Algunos derechos son considerados en algunas jurisdicciones como "preferidos" y solo admiten restricciones frente a un peligro claro y actual (v. gr., libertad de expresión, derechos electorales, etc.). La legislación que restringe estos derechos goza de una presunción de constitucionalidad débil. No obstante, el resto de los derechos (v. gr., de naturaleza económica) no gozan de una protección tan fuerte y, por ello, la legislación que los regula o restringe será superada solo cuando incurra en una clara arbitrariedad. En estos casos, puede decirse que la legislación goza de una presunción de constitucionalidad fuerte. En

29 Cfr. Hessick, F. A. "Rethinking the Presumption of Constitutionality". Ob. cit., 1451 y ss.

30 Cfr. ibídem, 1456. 
los casos en los que la legislación goza de una presunción de constitucionalidad débil, alcanzará con que el actor impugne la constitucionalidad de una ley para que se invierta la carga de argumentar en contra de quien defiende la regularidad del acto. En cambio, en los casos en que la legislación goza de presunción de constitucionalidad fuerte, quien la impugna debe argumentar que es claramente inconstitucional ${ }^{31}$.

$\mathrm{Al}$ respecto, ha de reconocerse que el modelo de Alexy es capaz de receptar la diferente intensidad o el diferente tipo de presunción de constitucionalidad del que gozan distintos derechos. En concreto, el mencionado modelo receptó esta clase de particularidades de los distintos sistemas de control de constitucionalidad en la variable de la ponderación relativa al "peso abstracto" de los derechos.

Resta mencionar que lo anterior no necesariamente supone que algunos sistemas de control de constitucionalidad sean mejores que otros. La racionalidad de cada sistema de control de constitucionalidad dependerá, en parte, de factores históricos, institucionales, de coherencia interna y democráticos.

Es posible que existan diferentes y razonables maneras de determinar cómo integrar los principios formales (democrático, republicano y del gobierno de la ley) con los derechos fundamentales. Esta posibilidad ha sido largamente aceptada por la denominada "tradición central de occidente"32.

Según dicha tradición, parte de la relevancia y de la capacidad del derecho para aportar razones para la acción y coordinar la vida social podría estar fundada en su capacidad para proveer soluciones valiosas cuando el razonamiento práctico general guarda silencio $u$ otorga muchas posibilidades razonables de comportamiento o posibilidades de coordinación de la vida social $^{33}$.

31 Cfr. Sánchez Gil, R. "La presunción de constitucionalidad”. Ob. cit., 380-383. Algo parecido a lo dicho sobre los derechos o libertades preferidas puede decirse sobre el derecho a la igualdad. Cfr. ibídem, 383 y ss.

32 Así la ha denominado Isaiah Berlin en su libro (1991). The Crooked Timber of Humanity: Chapters in the History of ldeas. New York. Knopf.

33 Un debate de algún modo vinculado con lo que se está exponiendo es el que se desata en torno a la tesis (atribuida a Dworkin) de que el Derecho siempre ofrece una única respuesta correcta. Algunos antecedentes de esta idea pueden encontrarse en Dworkin, R. (1977). Taking rights seriously. London. Duckworth. Traducción de Guastavino, M. (1984). Los derechos en serio. Barcelona. Ariel, 396 y ss. y 455 y ss. En El imperio de la justicia varias referencias hacen alusión a esta idea. Un ejemplo en Dworkin, R. (2012). El imperio de la justicia (trad. de C. Ferrari). Barcelona. Gedisa, 191. Existe todo un debate sobre el alcance de esta tesis y su evolución. Entre otros trabajos. cfr. Bix, B. (1995). Law, Language, and Legal Determinacy. Oxford. Clarendon Press, 77 y ss.; Coleman, J. (1995). “Truth and Objectivity in Law". Legal Theory 1, 48 y ss.; Endicott, T. (1996). "Ronald Dworkin y las consecuencias de la vaguedad" (trad. de J. J. Moreso y P. Navarro). Doxa 19 y en Palabras y reglas. Ensayos de Filosofía del Derecho. Ob. 
Aristóteles ya había advertido que las leyes establecidas para casos concretos y que no tienen en todas partes la misma fuerza hacen que "aquello que en un principio da lo mismo que sea así o de otra manera" (v. gr., que se deba sacrificar una cabra y no dos ovejas), "ya no d[é] lo mismo" y que, por ello, su cumplimiento termine resultando debido en justicia. En concreto, para Aristóteles, lo que establecen estas leyes es debido por un tipo de justicia "fundada en la convención y en la utilidad", en contraposición a lo que denominó la "justicia natural" 34 . Esta enseñanza continuó siendo aceptada durante buena parte de la edad media. En sentido similar al de Aristóteles, cabe recordar lo que afirmó Aquino sobre la imposibilidad real de derivar siempre una única respuesta moralmente correcta o razonable de los principios morales últimos (válidos por su mérito y no justificables, a su vez, por otros principios). A su juicio, esto "hace necesario que la razón humana proceda ulteriormente a sancionar algunas leyes particulares" 35 . En la actualidad, John Finnis es quien ha puesto mayor énfasis en recordar esta idea y aplicarla para la explicación del fenómeno jurídico actual ${ }^{36}$.

\section{c) Un modelo que en la práctica limita aún más la discrecionalidad legislativa}

Una consecuencia no buscada de que el modelo de Alexy resulte excesiva y artificialmente refinado es que, de ser tomado al pie de la letra, probablemente termine limitando al extremo la discrecionalidad legislativa. Si bien Alexy expresamente rechaza la tesis de la única respuesta jurídica correcta, el refinamiento de su modelo corre el riesgo de terminar promo-

cit., 93 y ss.; y Finnis, J. (1987). "On Reason and Authority in 'Law's Empire”. Law and Philosophy 6, 372 y ss. Bonorino ha publicado un libro en castellano al respecto. Cfr. Bonorino, P. R. (2002). Objetividad y verdad en el Derecho. Bogotá. Universidad Externado de Colombia. En 2006 se ha publicado un debate entre Massini y Moreno Rodríguez Alcalá sobre el alcance de esta tesis. Cfr. Massini Correas, C. I. (2006). "Dworkin, Finnis y la 'única respuesta correcta". En S. Legarre, A. Miranda Montecinos y C. Orrego. La lucha por el derecho natural. Santiago. Universidad de los Andes, 95-117 y Moreno Rodríguez Alcalá, R. "Respuestas correctas, justas y la persistencia del encanto del legalismo. Comentario a 'Dworkin, Finnis y la única respuesta correcta' del Prof. C. I. Massini C.”. En S. Legarre, A. Miranda Montecinos y C. Orrego. La lucha por el derecho natural. Ob. cit., 119-149.

34 Aristóteles. Ética a Nicómaco, V, 7, 1135a [se emplea la edición bilingüe a cargo de M. Araujo y J. Marías (1994). Madrid. Centro de Estudios Constitucionales].

35 Tomás de Aquino. Summa Theologiae, I-II q. 91, a. 3.

36 Cfr. Finnis, J. (2000). Ley natural y derechos naturales. Trad. de C. Orrego. Buenos Aires. Abeledo Perrot, 308 y sigs. 
viendo un resultado contrario al objetivo que se proponía: evitar un estado jurisdiccional de Derecho ${ }^{37}$.

\section{Elementos que ha de tener en cuenta una propuesta alternativa}

De lo anterior se puede concluir que un modelo alternativo tiene que tener aspiraciones más modestas en cuanto al nivel de detalle y certeza que es posible ofrecer para explicar el papel de los principios formales en la ponderación de los materiales. A su vez, una propuesta alternativa tiene que ser capaz de receptar el diferente papel que le reconocen a los principios formales los diferentes sistemas de control de constitucionalidad. Finalmente, tal propuesta debe aceptar que probablemente haya varios modos razonables de receptar y hacer intervenir a los principios formales en la ponderación de los materiales.

Hay que reconocer que los defensores de la teoría de la ponderación alexiana expresamente afirman que la ponderación "no es un procedimiento material para la fundamentación de respuestas únicas y justas"38. También aclaran que la ponderación no está orientada a la forma de fundamentar las premisas necesarias para llevarla adelante. En cambio, consideran que es solo "un procedimiento metodológico" o "una estructura de argumentación" o "una forma de argumentación" 39. Por ello, consideran que los principales peligros de la ponderación son externos a ella. En concreto, afirman que dichos peligros están relacionados con el modo en que es utilizada esta estructura o forma de argumentación y no con cómo es dicha estructura ${ }^{40}$.

Si bien el propio Alexy expresamente reconoce la discrecionalidad legislativa y no defiende la tesis de la única respuesta jurídica correcta (salvo como un mero ideal regulativo $)^{41}$, el mecanismo que propone para incorporar los principios formales en la ponderación de los materiales es tan complejo, parece pretender un nivel o grado de detalle y especificidad tan

37 Por más que el modelo de ponderación de Alexy sea muy refinado, no permite prever qué decidirán los órganos encargados de aplicar el Derecho frente a casos de conflictos entre principios constitucionales. Incluso, para algunos autores, tampoco permite someter las decisiones de dichos órganos a críticas racionales. Cfr. Moreso, J. J. (2010). "Conflictos entre derechos constitucionales y maneras de resolverlos". ARBOR 745, 825.

38 Portocarrero, J. A. (2016). “¿Peligros de la ponderación? La racionalidad de la ponderación en la interpretación de los derechos fundamentales”. Vox Juris 31, 82.

39 Ibídem, 82, 90 y 91.

40 Cfr. ibídem, 96.

41 Cfr. Alexy, R. (1988). "Sistema jurídico, principios jurídicos y razón práctica" (trad. de M. Atienza). Doxa 5, 151. 
elevado y le asigna al mencionado mecanismo tantas posibilidades de resultado que, en la práctica, parece terminar borrando con el codo lo escrito con la mano. Dicho de otro modo, la fórmula del peso "refinada" pareciera virtualmente negar tanto la posibilidad de la discrecionalidad legislativa estructural (cuyo origen sería un empate ponderativo), como la idea de que no existe para todo caso una única respuesta jurídica correcta.

Esta virtual negación de la discrecionalidad legislativa corre el riesgo de no tomarse en serio la relevancia de las dimensiones histórica, institucional y democrática que dan origen, entre otros, a los principios relativos al gobierno de la ley, la división de poderes y el que afirma que la legislación democrática es aquella que surge del procedimiento de toma decisión colectiva más racional y legítimo que puede existir. A su vez, la racionalización que Alexy propone es posible que produzca un resultado contrario a la exigencia de que el legislador democráticamente legitimado sea, en la mayor medida de lo posible, quien tome las decisiones importantes para la comunidad y, por tanto, exige que el ámbito de su discrecionalidad sea tan amplio como sea posible.

Como es fácil de advertir, estos problemas no son meramente externos a la estructura de ponderación propuesta por Alexy. En realidad, parecen ser fruto de lo artificialmente refinada que es la mencionada estructura o forma de argumentar.

Dicho refinamiento artificial de la ponderación tiene, además, el problema de que no refleja el diferente y, a la vez, razonable papel que le reconocen o pueden reconocer a los principios formales los distintos sistemas de control de constitucionalidad. Como se advirtió, no todos los sistemas de control de constitucionalidad son iguales y no todos les reconocen a los principios formales exactamente el mismo papel en la ponderación de los principios materiales.

Algunos sistemas de control de constitucionalidad les reconocen a los principios formales la capacidad de trasladar la carga de la argumentación y/o de la prueba a quien solicita la declaración de inconstitucionalidad de una ley democrática ${ }^{42}$. Otros, trasladan solo en algunos casos al solicitante de la inconstitucionalidad la carga de su prueba ${ }^{43}$. Incluso algunos sistemas les reconocen una especial deferencia a las definiciones de las premisas fácticas realizadas por el legislador democrático, pero no le reconocen lo mismo a la definición de las premisas normativas ofrecidas por dicho órgano ${ }^{44}$.

42 Cfr. Sánchez Gil, R. "La presunción de constitucionalidad”. Ob. cit., 377 y ss.

43 Cfr. Rivers, J. (2014). "The Presumption of Proportionality”. The Modern Law Review $77,410$.

44 Cfr. Hessick, F. A. "Rethinking the Presumption of Constitutionality". Ob. cit., 1455 y Ss. 
En definitiva, un modelo alternativo debe tener en cuenta no solo el hecho de que la legislación sea democrática, sino también que los distintos sistemas de control de constitucionalidad son fruto de un proceso histórico e institucionalizado que concretiza uno de los muchos modos razonables de integrar el respeto por la legislación democrática y por los derechos fundamentales. A su vez, este modelo alternativo debe aceptar que él solo será capaz de orientar a quien tenga que llevar adelante la mencionada ponderación y no pretender limitar artificialmente cada paso de su razonamiento de un modo encorsetado, rígido o excesivamente detallado que no refleja o explica la realidad a la que pretende aplicarse.

Una propuesta alternativa puede buscar explicar a los principios formales como normas con una capacidad directiva o de guía limitada, que han sido determinadas por medio de reglas procesales constitucionales y que cumplen primordialmente una función de fundamentación de dichas reglas que prescriben presumir la constitucionalidad de las leyes democráticas. Si bien estas reglas procesales no son reglas de competencia, afectan el alcance de la competencia (entendida en un sentido lato) de los tribunales encargados de controlar la constitucionalidad de las leyes ${ }^{45}$.

Un principio con capacidad de guía limitada es aquel que solo ofrece algunos de los elementos que pasarán a tener en cuenta quienes abordan el proceso racional de tomar una decisión. Esto es así porque quienes han de aplicar estos principios no pueden concluir de manera razonable simplemente apelando a cualquiera de estos principios. Por ello, para aplicar estos principios es necesario ponerlos en relación con otras razones normalmente recogidas en otros principios y reglas. Esto significa que estos principios solo son capaces de ofrecer una pauta para el razonamiento jurídico que se volverá definitiva únicamente después de su puesta en relación o ponderación contra otras normas cuyas calificaciones normativas sean incompatibles y también tengan un carácter prima facie. Otra característica de estos principios es que no prevén sus situaciones de aplicación, sino que, más bien, parecen mostrar un bien o fin que ha de ser buscado y que es intrínseco al propio principio. Incluso más, parecen no especificar tampoco cómo se llega al estado de cosas o bien que los realiza.

Dada la necesidad que tienen estos principios de ser determinados y de la existencia de reglas procesales constitucionales que realizan dicha tarea, el principal papel de los principios formales en la ponderación de los materiales parece ser el de fundar, transparentar las razones subyacen-

45 Sobre la distinción entre principios con diferente capacidad directiva o de guía, cfr. Etcheverry, J. B. (2019). "An Approach to Legal Principles Based on Their Justifying Function". Canadian Journal of Law \& Jurisprudence 32, 329. 
tes, ayudar a explicar y limitar las reglas procesales constitucionales que establecen que ha de presumirse la constitucionalidad de las leyes, salvo argumento y/o prueba en contrario ${ }^{46}$. Estas reglas suponen, como ha sido advertido por la doctrina, que quien reclame la inconstitucionalidad de una ley cargará con el peso de la argumentación y/o de la prueba de dicha inconstitucionalidad. En palabras de la propuesta que se viene desarrollando, las diferentes reglas que ordenan con distinta intensidad la presunción de constitucionalidad de las leyes serían una determinación posible de los principios formales.

\section{Conclusión}

Como ha sido explicado, existe una preocupación creciente por el riesgo de que los sistemas de control de constitucionalidad terminen sobredimensionando el rol de los derechos fundamentales en el sistema jurídico, sobreconstitucionalizándolo y poniendo en riesgo el Estado democrático de Derecho frente a un posible Estado jurisdiccional de Derecho.

Frente a este riesgo, Alexy propone un modelo de ponderación de los derechos fundamentales que denomina "refinado" y que tiene en cuenta el papel que desempeñan en esta operación los "principios formales". Para Alexy, los principios formales exigen el cumplimiento de las reglas que son impuestas por una autoridad legitimada para crearlas. Dentro de los principios formales destaca el "democrático", según el cual, idealmente, el procedimiento de toma de decisiones democrático es el más racional y legítimo que puede existir. Este modelo es calificado como "epistémico" porque considera que los principios formales juegan un papel en la justificación de la variable "fiabilidad epistémica" de las premisas que se incorporan en el razonamiento para aplicar principios.

Alexy expresamente reconoce que la ponderación no garantiza una única respuesta correcta y justa. No obstante, en la práctica complejiza de tal manera la fórmula del peso, al punto de transformarla en una ecuación aritmética tan enrevesada que cada vez menos se parece o explica la experiencia real de los operadores jurídicos cuando aplican principios materiales y, para ello, también tienen en cuenta a los principios formales.

Por otra parte, esta complejización del modelo de la ponderación corre el riesgo de terminar generando un efecto contrario al buscado. Puede virtualmente terminar rechazando toda discrecionalidad legislativa.

46 Cfr. ibídem, 332. 
En tercer lugar, el mencionado refinamiento artificial de la ponderación tiene además el desafío de que no refleja el diferente y, a la vez, razonable papel que les reconocen a los principios formales los distintos sistemas de control de constitucionalidad.

Es deseable que un modelo alternativo explicite aspiraciones más modestas en cuanto al nivel de detalle y certeza que es posible ofrecer, que sea capaz de receptar el diferente papel que les reconocen a los principios formales los diferentes sistemas de control de constitucionalidad y que, finalmente, reconozca que probablemente haya varios modos razonables de receptar y hacer intervenir a los principios formales en la ponderación de los materiales.

Finalmente, un posible modo alternativo de concebir el papel de los principios formales en la ponderación de los materiales es aquel que advierte que ellos cumplen principalmente con la función de fundar, trasparentar las razones subyacentes y explicar las reglas procesales constitucionales que establecen que ha de presumirse la constitucionalidad de las leyes, salvo argumento y/o prueba en contrario.

\section{Bibliografía}

Alexy, R. (2016). "Principios formales. Algunas respuestas a los críticos". En J. Portocarrero (ed.). Ponderación y discrecionalidad. Bogotá. Universidad del Externado.

Alexy, R. (1988). "Sistema jurídico, principios jurídicos y razón práctica" (trad. de M. Atienza). Doxa 5.

Aristóteles (1994). Ética a Nicómaco, edición bilingüe a cargo de M. Araujo y J. Marías. Madrid. Centro de Estudios Constitucionales.

Atienza, M. (2010). "A vueltas con la ponderación”. Anales de la Cátedra de Francisco Suárez 44

Berlin, I. (1991). The Crooked Timber of Humanity: Chapters in the History of ldeas. New York. Knopf.

Bernal Pulido, C. (2006). "La racionalidad de la ponderación". Revista Española de Derecho Constitucional 77.

Bix, B. (1995). Law, Language, and Legal Determinacy. Oxford. Clarendon Press.

Bonorino, P. R. (2002). Objetividad y verdad en el Derecho. Bogotá. Universidad Externado de Colombia.

Borowski, M. (2016). "Principios formales y fórmula del peso". En J. Portocarrero (ed.). Ponderación y discrecionalidad. Bogotá. Universidad del Externado.

Coleman, J. (1995). "Truth and Objectivity in Law". Legal Theory 1.

Dworkin, R. (2012). El imperio de la justicia (trad. de C. Ferrari). Barcelona. Gedisa.

Dworkin, R. (1977). Taking rights seriously. London. Duckworth. Traducción de M. Guastavino (1984). Los derechos en serio. Barcelona. Ariel. 
Endicott, T. (1966). "Ronald Dworkin y las consecuencias de la vaguedad" (trad. de J. J. Moreso y P. Navarro). Doxa 19 y en Palabras y reglas. Ensayos de Filosofía del Derecho.

Etcheverry, J. B. (2019). "An Approach to Legal Principles Based on Their Justifying Function”. Canadian Journal of Law \& Jurisprudence 32.

Finnis, J. (1987). “On Reason and Authority in 'Law's Empire”. Law and Philosophy 6.

Finnis, J. (2000). Ley natural y derechos naturales. Trad. de C. Orrego. Buenos Aires. Abeledo Perrot.

García Amado, J. A. (2007). "El juicio de ponderación y sus partes. Una crítica”. En R. Alexy (ed.). Derechos sociales y ponderación. $2^{\text {a }}$ ed. Madrid. Fundación Coloquio Jurídico Europeo.

Hart, H. L. A. (1983). "American Jurisprudence through English Eyes: The Nightmare and the Noble Dream". En Essays in Jurisprudence and Philosophy. Oxford. Oxford University Press.

Hessick, F. A. (2010). "Rethinking the Presumption of Constitutionality". Notre Dame Law Review 85.

Massini Correas, C. I. (2006). "Dworkin, Finnis y la 'única respuesta correcta". En S. Legarre, A. Miranda Montecinos y C. Orrego. La lucha por el derecho natural. Santiago. Universidad de los Andes.

Moreno Rodríguez Alcalá, R. (2006). "Respuestas correctas, justas y la persistencia del encanto del legalismo. Comentario a 'Dworkin, Finnis y la única respuesta correcta' del Prof. C. I. Massini C.”. En S. Legarre, A. Miranda Montecinos y C. Orrego. La lucha por el derecho natural. Santiago. Universidad de los Andes.

Moreso, J. J. (2010). "Conflictos entre derechos constitucionales y maneras de resolverlos". ARBOR 745.

Portocarrero, J. A. (2016). “¿Peligros de la ponderación? La racionalidad de la ponderación en la interpretación de los derechos fundamentales”. Vox Juris 31, 82.

Portocarrero, J. (2016). "El problema de los principios formales en la doctrina de la ponderación de Robert Alexy: Del in dubio pro libertate al in dubio pro legislato$r$ ". En J. Portocarrero (ed.). Ponderación y discrecionalidad. Bogotá. Universidad del Externado.

Rivers, J. (2014). “The Presumption of Proportionality". The Modern Law Review 77, 410.

Sánchez Gil, R. (2008). "La presunción de constitucionalidad". En E. Ferrer MacGregor y A. Zaldívar Lelo de Larrea (coords.). La ciencia del derecho procesal constitucional. Estudios en homenaje a Héctor Fix-Zamudio en sus cincuenta años como investigador del Derecho. T. VIII. México. UNAM.

Sieckmann, J. (2016). "Principios formales". En J. Portocarrero (ed.). Ponderación y discrecionalidad. Bogotá. Universidad del Externado.

Tomás de Aquino. Summa Theologiae, I-II. 